Supporting Information for

\title{
Effect of Alkanediol Additives on the Properties of Polyphenylene-based Proton Exchange Membranes
}

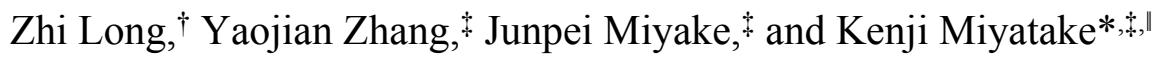

†Interdisciplinary Graduate School of Medicine and Engineering, University of Yamanashi, 4

Takeda, Kofu, Yamanashi 400-8510, Japan

†lean Energy Research Center, University of Yamanashi, 4 Takeda, Kofu, Yamanashi 4008510, Japan

"Fuel Cell Nanomaterials Center, University of Yamanashi, 4-3 Takeda, Kofu 400-8511, Japan

*Corresponding author

E-mail address: miyatake@yamanashi.ac.jp (K. Miyatake). 
Measurements. ${ }^{1} \mathrm{H}(500 \mathrm{MHz}) \mathrm{NMR}$ spectra were obtained by a JEOL JNM-ECA 500 spectrometer using DMSO- $d_{6}$ as a solvent and tetramethylsilane as an internal reference at $80^{\circ} \mathrm{C}$. Fourier transform infrared (FT-IR) spectra of the membranes were measured on JASCO FT/IR6100. The IEC of the membrane was measured by acid base titration. Ca. $20 \mathrm{mg}$ of membrane was immersed in a $2 \mathrm{M} \mathrm{NaCl}$ for $24 \mathrm{~h}$ at room temperature to release proton, which was titrated with a standard $0.01 \mathrm{M}$ aqueous $\mathrm{NaOH}$ solution at room temperature, via ion exchange reaction.

For the sample of transmission electron microscopy (TEM), the membrane was stained in 0.5 $\mathrm{M} \mathrm{Pb}(\mathrm{OAc})_{2}$ aqueous solution, embedded in epoxy resin, sectioned to $50 \mathrm{~nm}$ thickness, and placed on copper grids. Images were obtained via Hitachi H-9500 microscope with an accelerating voltage of $200 \mathrm{kV}$.

The small angle X-ray scattering (SAXS) was measured by a Rigaku NANOViewer diffractometer equipped with a temperature/humidity-controlled chamber. The membrane was equilibrated for more than $2 \mathrm{~h}$ under the tested condition (that is, $80{ }^{\circ} \mathrm{C}$ at different relative humidity). Dimensional stability was tested by comparing the dimensional difference between wet and dry membranes. Dimension of dry membrane was measured after drying the membrane in vacuum at $80{ }^{\circ} \mathrm{C}$ for $12 \mathrm{~h}$. Dimension of wet membrane was measured after immersing the membrane in deionized water at $60{ }^{\circ} \mathrm{C}$ for $6 \mathrm{~h}$ and removing surface water quickly.

Water uptake and in-plane proton conductivity of the membranes were measured simultaneously at $80{ }^{\circ} \mathrm{C}$ with a solid electrolyte analyzer system (MSBAD-V-FC, Bel Japan Co.) in a temperature- and humidity-controllable chamber. The weight was measured by a magnetic suspension balance. The dry weight of membrane was provided after drying at $80{ }^{\circ} \mathrm{C}$ in vacuum for $3 \mathrm{~h}$ and the wet weight was obtained after exposure to the testing humidity for more than $2 \mathrm{~h}$. Water uptake $(($ wet weight - dry weight $) /$ dry weight $\times 100)$ was obtained. The in-plane proton 
conductivity was tested with a four-probe conductivity cell connected with an ac impedance analyzer (Solartron 1255B and 1287, Solartron Inc.). Ion-conducting resistance was obtained in the frequency range of 1 to $10^{5} \mathrm{~Hz}$. The proton conductivity ( $\delta$ ) was calculated from the following equation: $\delta=1 /(\mathrm{A} \times \mathrm{R})$, where 1 is the distance between the two reference electrodes and $\mathrm{A}$ is the cross-sectional area. The dynamic mechanical analyses (DMA) were carried out with an ITK DVA-225 dynamic viscoelastic analyzer to evaluate the humidity dependence of the storage moduli $\left(E^{\prime}\right)$, loss moduli $\left(E^{\prime \prime}\right)$, and $\tan \delta\left(=E^{\prime \prime} / E^{\prime}\right)$ of the membranes. The sample was tested under a humidity range from 0 to $90 \%$ relative humidity at $80{ }^{\circ} \mathrm{C}$ at a humidification rate of $1 \% \mathrm{RH} \mathrm{min}^{-1}$. The tensile strength was measured with a Shimadzu AGS-J 500N universal testing instrument attached with a Toshin Kogyo Bethel-3A temperature and humidity controllable chamber at $80{ }^{\circ} \mathrm{C}$ and $60 \% \mathrm{RH}$. Samples cut into a dumbbell shape [DIN-53504-S3, $35 \mathrm{~mm} \times 6 \mathrm{~mm}$ (total) and $12 \mathrm{~mm} \times 2 \mathrm{~mm}$ (test area)] were used. After equilibrating under the controlled temperature and humidity conditions for at least $2 \mathrm{~h}$, the stress-strain curve was obtained at a stretching rate of $10 \mathrm{~mm} \mathrm{~min}^{-1}$.

Hydrogen and oxygen permeability was measured using a GTR-Tech 20XFYC gas permeation measurement apparatus. The concentrations of the permeated gases were quantified by a Yanaco G2700T gas chromatograph with a Porapak-Q column and a thermal conductivity detector. Argon and helium were used as the carrier gases for the measurement of hydrogen and oxygen, respectively. Membranes were placed in the center of the cells having gas inlet/outlet on both sides of the membranes. The test gas was supplied onto one side of the membrane, and the carrier gas was supplied onto the other side of the membrane. The same humidity conditions were applied to both test and carrier gases to ensure homogeneous wetting of the membranes. The membrane was equilibrated until stable permeation data were obtained. The gas permeation 
coefficient, $Q\left(\mathrm{~cm}^{3}\right.$ (STD) $\mathrm{cm} \mathrm{cm}^{-2} \mathrm{~s}^{-1} \mathrm{cmHg}^{-1}$ ), was calculated by the following equation: $Q=$ $273 / T \times 1 / A \times B \times 1 / t \times l \times 1 /\left(76-P_{\mathrm{H} 2 \mathrm{O}}\right)$, where $T(\mathrm{~K})$ is the absolute temperature, $A\left(\mathrm{~cm}^{2}\right)$ is the permeation area, $B\left(\mathrm{~cm}^{3}\right)$ is the volume of permeated test gas, $t(\mathrm{~s})$ is the sampling time, $l(\mathrm{~cm})$ is the thickness of the membrane, and $P_{\mathrm{H} 2 \mathrm{O}}(\mathrm{cmHg})$ is the water vapor pressure.

For the oxidative stability test, the membranes (ca. $20 \mathrm{mg}$ ) were immersed in $50 \mathrm{~mL}$ of Fenton's solution (aqueous solution containing 3\% $\mathrm{H}_{2} \mathrm{O}_{2}$ and 2 ppm $\mathrm{Fe}^{2+}$ from Iron(II) sulfate heptahydrate $\left.\left(\mathrm{FeSO}_{4} 7 \mathrm{H}_{2} \mathrm{O}\right)\right)$. After shaking at $80{ }^{\circ} \mathrm{C}$ for $1 \mathrm{~h}$, the recovered membranes were washed with $2 \mathrm{M} \mathrm{HCl}$ and water several times.

A catalyst paste was prepared by mixing Pt/CB catalyst (TEC10E50E, Tanaka Kikinzoku Kogyo K. K.), Nafion dispersion (IEC = 0.95-1.03 meq g-1, D-521, Du Pont), deionized water and ethanol by ball milling for $30 \mathrm{~min}$. The mass ratio of Nafion ionomer to the carbon support (I/C) was adjusted to 0.7 . The catalyst-coated membranes (CCMs) were prepared by spraying the catalyst paste on both sides of the SPP-QP-BA (C4) membrane by the pulse-swirl-spray (PSS) technique. The CCMs were dried at $60^{\circ} \mathrm{C}$ overnight and hot-pressed at $140{ }^{\circ} \mathrm{C}$ and $1.0 \mathrm{MPa}$ for 3 min. The geometric area and the Pt loading amount in the catalyst layer (CL) were $4.41 \mathrm{~cm}^{2}$ and $0.50 \pm 0.05 \mathrm{mg} \mathrm{cm}^{-2}$, respectively.

To evaluate the fuel cell performance, the polarization curves were measured at $100 \% \mathrm{RH}$ and $80{ }^{\circ} \mathrm{C}$. Pure $\mathrm{H}_{2}$ and $\mathrm{O}_{2}$ (or air) were supplied to the anode and the cathode, respectively. The gas utilizations at the anode and the cathode were $70 \%$ and $40 \%$, respectively. The high frequency resistance (HFR) of the cell was measured with an ac milliohmmeter (Model 3356, Tsuruga Electric Corporation) at $1.0 \mathrm{kHz}$. 
Table S1. $m$ - / p-Phenylene Ratio of the Polymers

\begin{tabular}{|c|c|c|c|c|c|c|}
\hline \multirow{2}{*}{ Polymer } & \multicolumn{3}{|c|}{ Feed monomer (mmol) } & \multicolumn{2}{|c|}{ Phenylene $^{a}(\mathrm{mmol})$} & \multirow{2}{*}{$\begin{array}{c}m-/ p- \\
\text { Phenylene ratio }\end{array}$} \\
\hline & SP & QP & BA & $m-$ & $p-$ & \\
\hline $\mathrm{SPP}-\mathrm{QP}^{b}$ & 2.52 & 1.10 & - & 4.40 & 3.62 & 1.22 \\
\hline SPP-QP-BA & 3.00 & 1.44 & 0.3 & 5.76 & 4.74 & 1.22 \\
\hline
\end{tabular}

${ }^{a}$ Calculated from the feed monomers for polymerization. ${ }^{b}$ Data from our previous literature (Sci. $A d v$. 2017, 3, eaao0476).

Table S2. Feed Molar Ratio ${ }^{a}$, IEC, and Solubility of Membranes

\begin{tabular}{|c|c|c|c|c|c|c|}
\hline \multirow{2}{*}{ Membrane } & \multirow{2}{*}{$-\mathrm{SO}_{3} \mathrm{H}^{b} /-\mathrm{COOH}^{b} /-\mathrm{OH}^{c}$} & \multirow{2}{*}{$\begin{array}{c}\mathrm{IEC}^{d} \\
\left(\mathrm{meq} \mathrm{g}^{-1}\right)\end{array}$} & \multicolumn{4}{|c|}{ Solubility ${ }^{e}$} \\
\hline & & & $\mathrm{H}_{2} \mathrm{O}$ & DMAc & DMSO & NMP \\
\hline SPP-QP-BA & $2.85 / 0.28 /-$ & 2.4 & - & + & + & + \\
\hline SPP-QP-BA (C4) & $2.85 / 0.28 / 1.11$ & 2.2 & - & +- & +- & +- \\
\hline SPP-QP-BA (C8) & $2.85 / 0.28 / 0.68$ & 2.2 & - & +- & +- & +- \\
\hline SPP-QP-BA (C12) & $2.85 / 0.28 / 0.49$ & 2.2 & - & +- & +- & +- \\
\hline
\end{tabular}

${ }^{a}$ In all cases, the same precursor polymer (SPP-QP-BA, titrated IEC $\left.=2.4 \mathrm{meq} \mathrm{g}^{-1}\right)$ was used, and the amount of the additive (alkane diols) was set to be $5 \mathrm{wt} \%$ of SPP-QP-BA. ${ }^{b}$ Calculated from the feed SPP-QP-BA. ${ }^{c}$ Calculated from the feed alkane diols. ${ }^{d}$ Obtained by titration. ${ }^{e}$ After heating at $80{ }^{\circ} \mathrm{C}$ for $1 \mathrm{~h}$. - : insoluble, +- : partly soluble, and + : soluble. 
Table S3. Dimensional Change and Water Uptake of Membranes ${ }^{a}$

\begin{tabular}{cccc} 
& \multicolumn{2}{c}{ Dimensional change $^{2}$} & Water uptake $(\%)$ \\
\cline { 2 - 3 } Membrane & In-plane $^{b}(\%)$ & Through-plane $^{c}(\%)$ & \\
SPP-QP & 15 & 4 & 41 \\
SPP-QP-BA & 9 & 12 & 27 \\
SPP-QP-BA (C4) & 6 & 6 & 23 \\
SPP-QP-BA (C8) & 9 & 10 & 25 \\
SPP-QP-BA (C12) & 17 & 16 & 29 \\
\hline
\end{tabular}

${ }^{a}$ The change was measured between dry state (in vacuo at $80^{\circ} \mathrm{C}$ for $12 \mathrm{~h}$ ) and wet state (in deionized water at $60{ }^{\circ} \mathrm{C}$ for $6 \mathrm{~h}$ ). ${ }^{b}$ In-plane dimensional change was calculated from the formula as follows: $\left(S_{w e t}-S_{\text {dry }}\right) / S_{\text {dry }} \times 100 \%$, where $S_{\text {dry }}$ was the surface area of the dry membrane, and $\mathrm{S}_{\text {wet }}$ was the surface area of the wet membrane. ${ }^{c}$ Through-plane dimensional change was calculated from the formula as follows: $\left(h_{w e t}-h_{d r y}\right) / h_{d r y} \times 100 \%$, where $h_{\text {dry }}$ was the thickness of the dry membrane, and $h_{\text {wet }}$ was the thickness of the wet membrane. ${ }^{d}$ Water uptake was calculated from the formula as follows: $\left(m_{\text {wet }}-m_{\text {dry }}\right) / m_{\text {dry }} \times 100 \%$, where $m_{\text {dry }}$ was the weight of the dry membrane, and $\mathrm{m}_{\text {wet }}$ was the weight of the wet membrane. 

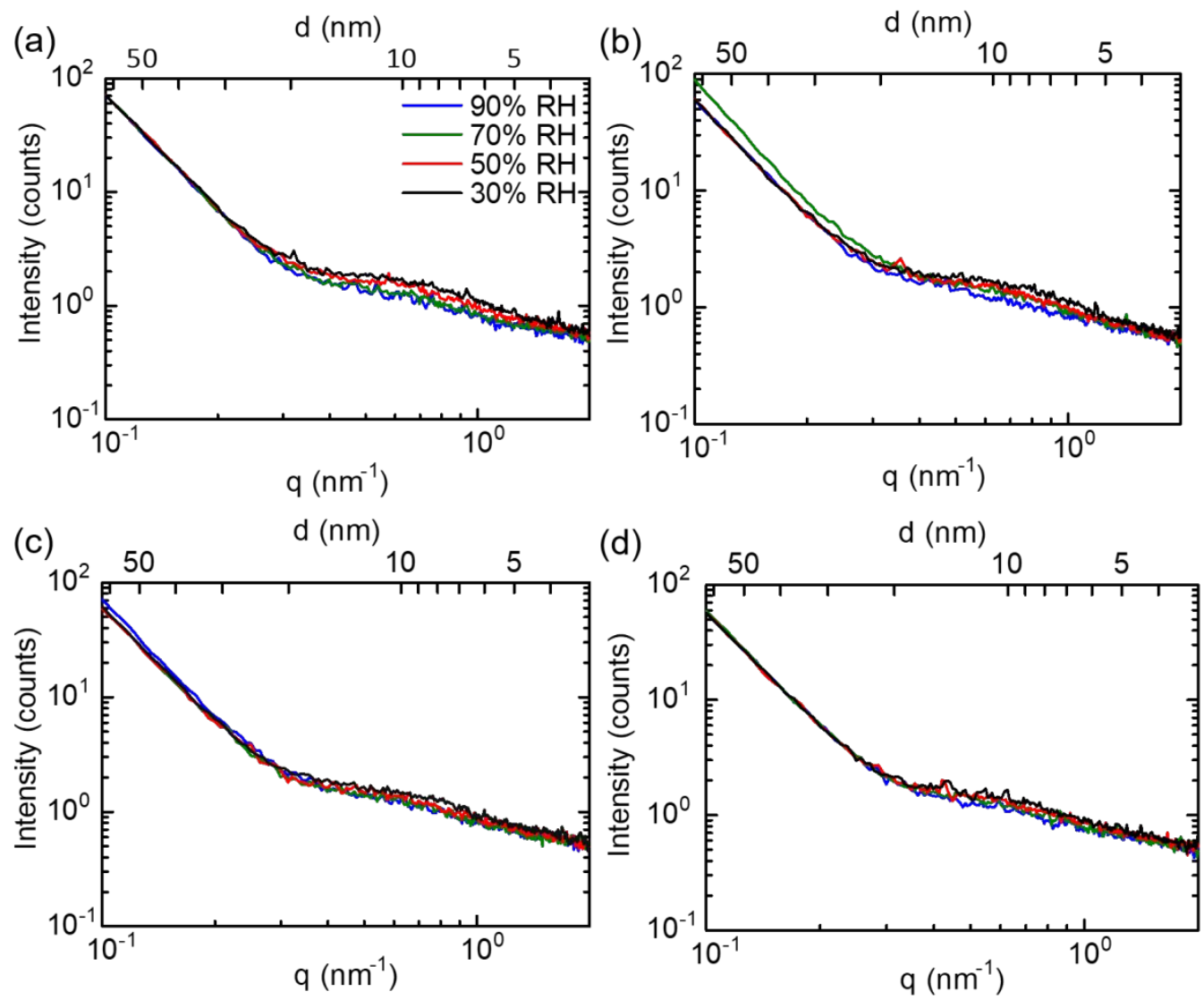

Figure S1. SAXS profiles of (a) SPP-QP-BA and the composite membranes (b) SPP-QP-BA (C4), (c) SPP-QP-BA (C8), (d) SPP-QP-BA (C12) at $80^{\circ} \mathrm{C}$. 


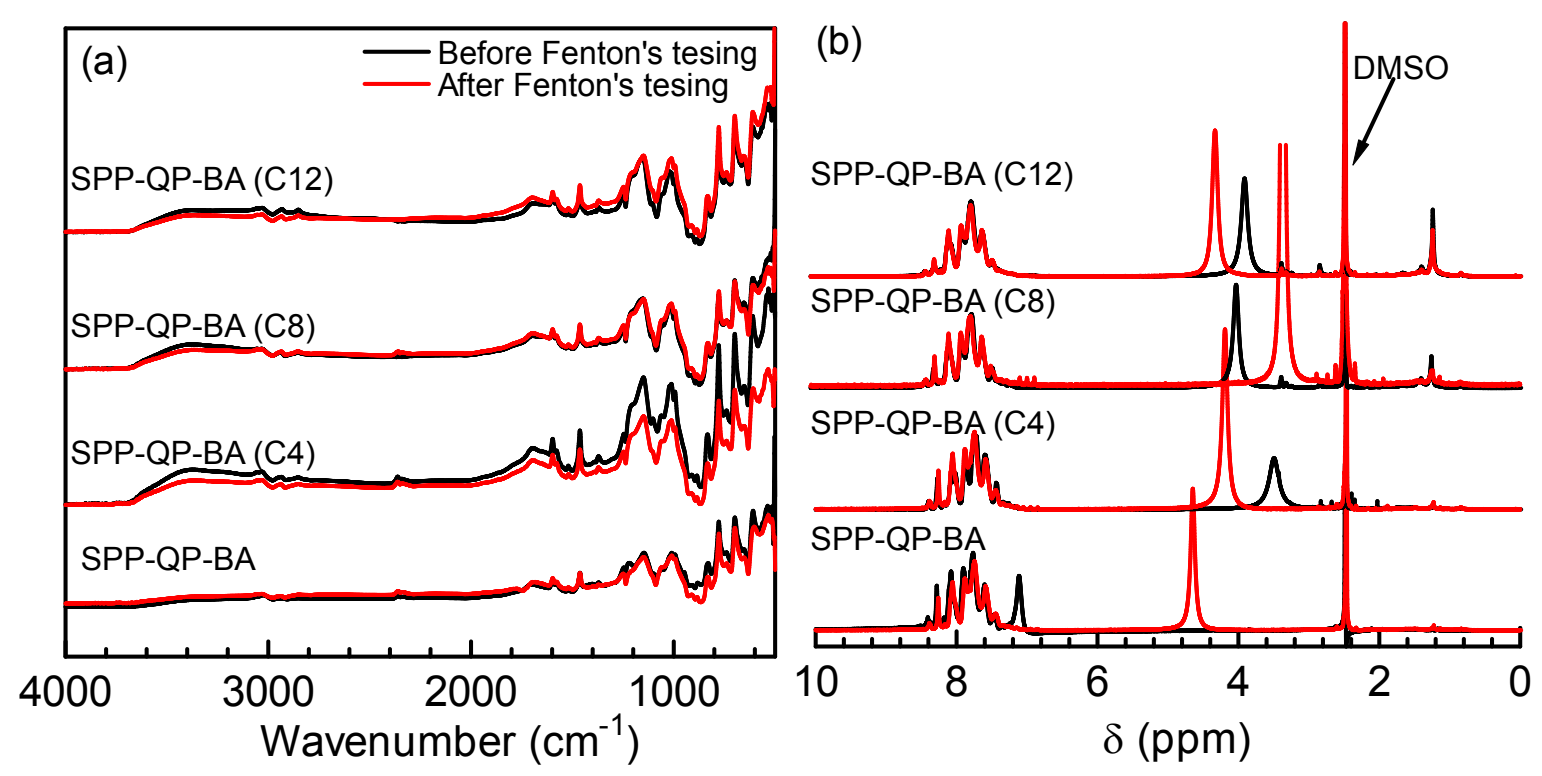

Figure S2. (a) FT-IR spectra and (b) ${ }^{1} \mathrm{H}$ NMR spectra in DMSO- $d_{6}$ at $80{ }^{\circ} \mathrm{C}$ of the SPP-QP-BA (Cn) and SPP-QP-BA membranes before and after the Fenton's test. 

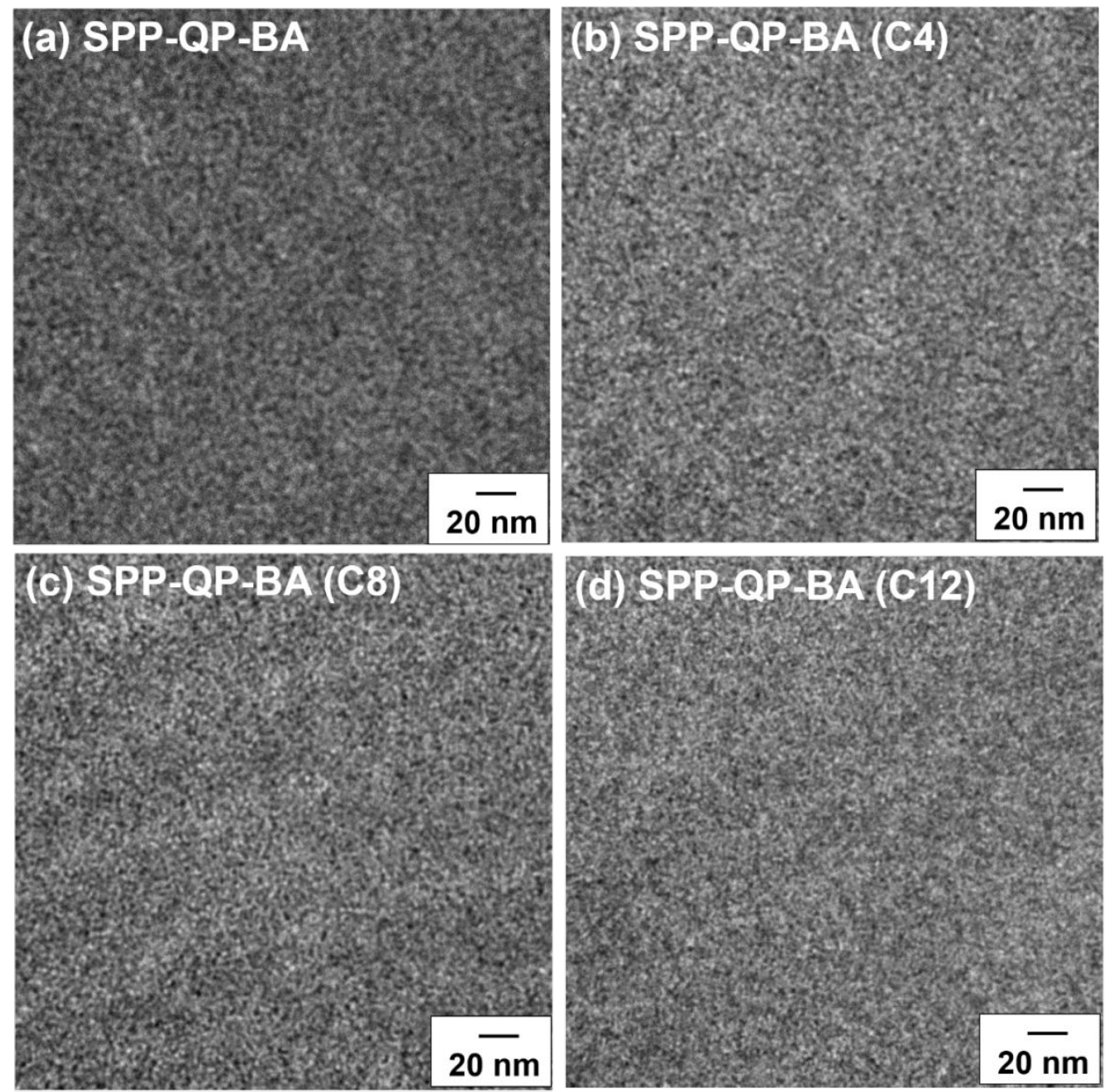

Figure S3. TEM images of (a) SPP-QP-BA, (b) SPP-QP-BA (C4), (c) SPP-QP-BA (C8), and (d) SPP-QP-BA (C12) after the Fenton's test. 

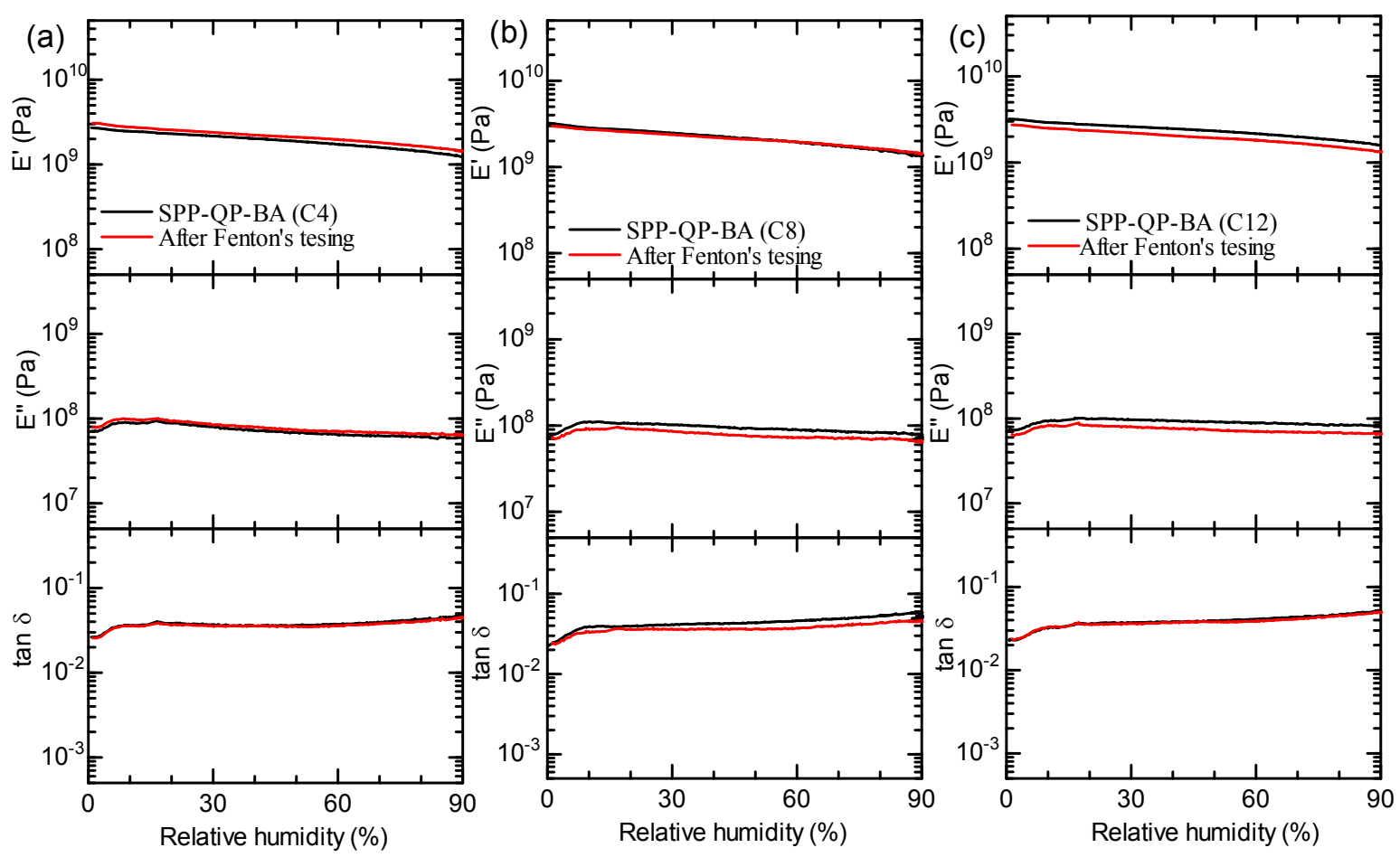

Figure S4. The effect of the Fenton's test on the viscoelastic properties of membranes at $80{ }^{\circ} \mathrm{C}$ as a function of RH; (a) SPP-QP-BA (C4), (b) SPP-QP-BA (C8), and (c) SPP-QP-BA (C12). 


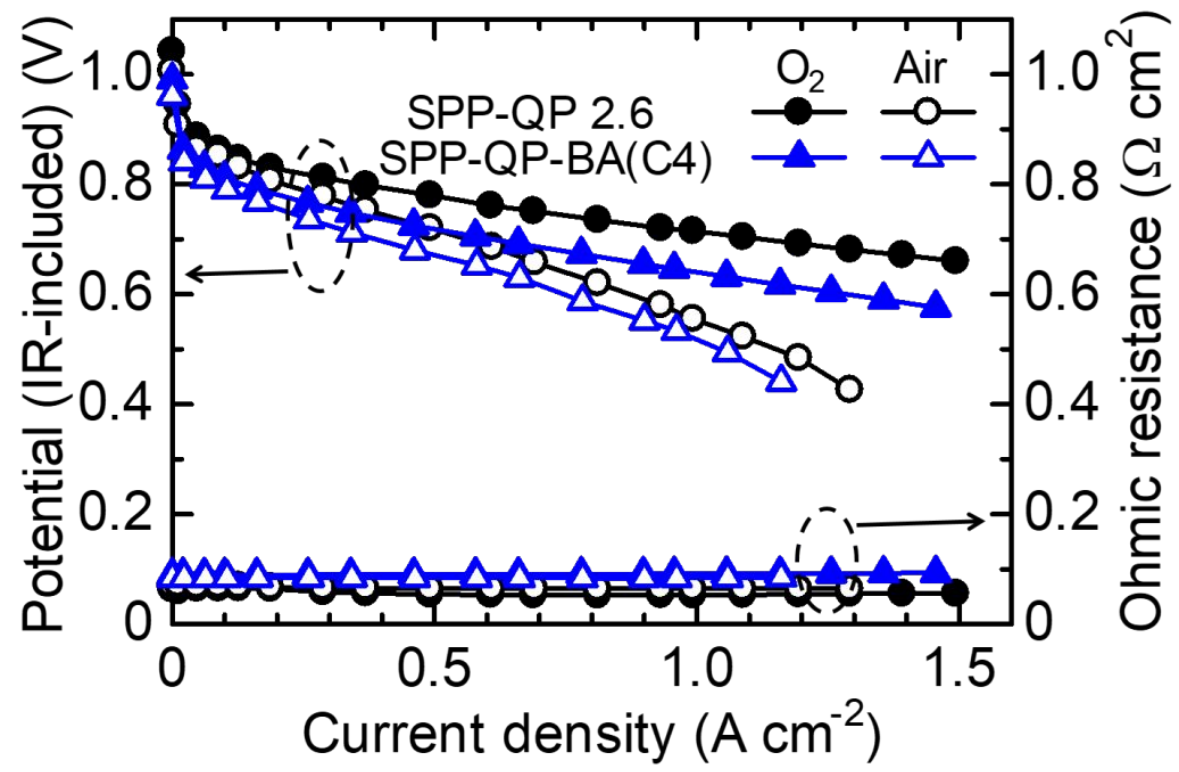

Figure S5. $I R$-included polarization curves and ohmic resistances for SPP-QP ${ }^{[1]}\left(2.6 \mathrm{meq}^{-1}\right)$ and SPP-QP-BA (C4) $\left(2.2 \mathrm{meq} \mathrm{g}^{-1}\right)$ cells at $80{ }^{\circ} \mathrm{C}$ and $100 \% \mathrm{RH}$. The Pt loading amounts were $0.50 \pm 0.05 \mathrm{mg} \mathrm{cm}^{-2}$ for both electrodes. Pure hydrogen and oxygen / air were supplied to the anode and cathode, respectively, without back pressure. The gas utilizations at the anode and the cathode were $70 \%$ and $40 \%$, respectively.

\section{Reference}

[1] Miyake, J.; Taki, R.; Mochizuki, T.; Shimizu, R.; Akiyama, R.; Uchida, M.; Miyatake, K. Design of Flexible Polyphenylene Proton-conducting Membrane for Next-generation Fuel Cells. Sci. $A d v$. 2017, 3, eaao0476. 